Article

\title{
Exploring the Dynamic Mechanisms of Farmland Abandonment Based on a Spatially Explicit Economic Model for Environmental Sustainability: A Case Study in Jiangxi Province, China
}

\author{
Hualin Xie *, Peng Wang * and Guanrong Yao \\ Institute of Poyang Lake Eco-economics, Jiangxi University of Finance and Economics, \\ Nanchang 330013, China; E-Mail: yaoguanrong@aliyun.com \\ * Authors to whom correspondence should be addressed; E-Mails: xiehualin@jxufe.edu.cn (H.X.); \\ landuse2008@126.com (P.W.); Tel.: +86-791-8381-0957 (H.X.); Fax: +86-791-8381-0892 (H.X.).
}

Received: 7 January 2014; in revised form: 4 March 2014 / Accepted: 5 March 2014 /

Published: 11 March 2014

\begin{abstract}
Farmland abandonment has important impacts on biodiversity and ecosystem recovery, as well as food security and rural sustainable development. Due to rapid urbanization and industrialization, farmland abandonment has become an increasingly important problem in many countries, particularly in China. To promote sustainable land-use management and environmental sustainability, it is important to understand the socioeconomic causes and spatial patterns of farmland abandonment. In this study, we explored the dynamic mechanisms of farmland abandonment in Jiangxi province of China using a spatially explicit economical model. The results show that the variables associated with the agricultural products yield are significantly correlated with farmland abandonment. The increasing opportunity cost of farming labor is the main factor in farmland abandonment in conjunction with a rural labor shortage due to rural-to-urban population migration and regional industrialization. Farmlands are more likely to be abandoned in areas located far from the villages and towns due to higher transportation costs. Additionally, farmers with more land but lower net income are more likely to abandon poor-quality farmland. Our results support the hypothesis that farmland abandonment takes place in locations in which the costs of cultivation are high and the potential crop yield is low. In addition, our study also demonstrates that a spatially explicit economic model is necessary to distinguish between the main driving forces of farmland abandonment. Policy implications are also provided for potential future policy decisions.
\end{abstract}

Keywords: farmland abandonment; environmental sustainability; land marginalization; ecosystem recovery; spatial economic model; sustainable land use; GIS 


\section{Introduction}

Changes in land use and land cover are critically important to understanding global climate change, food security, soil degradation, ecosystem dynamics, and human-environment interactions [1-3]. Generally, agricultural land use changes include farmland expansion due to land exploitation, farmland abandonment induced by rural-to-urban population migration, and conversion associated with urbanization and industrialization [4]. Farmland abandonment caused by marginalization of agriculture is a common phenomenon in European, North American, and certain newly industrialized countries. Since the late 1980s, farmland abandonment has continued in the mountain areas of Western Europe, Japan, and Eastern Europe and Mediterranean countries, such as Portugal, Spain, and Italy [5-9]. In China, land abandonment has been an increasingly important problem since the 1990s [10]. Rapid loss of agricultural land worried the central government [11].

Recently, farmland abandonment has received much attention from various disciplines because of its important impacts on biodiversity and ecosystem recovery, as well as food security and rural sustainable development [4,12-14]. This issue includes determination of where farmland abandonment takes place and why it needs to be addressed. A better understanding of the driving mechanisms underlying farmland abandonment is necessary for improved land use planning and farmland protection $[15,16]$.

Studies have shown that the determinants of farmland abandonment at the local scale include topographical conditions (e.g., elevation and slope) [17], soil properties (e.g., soil depth and soil erosion) [18], climate conditions [19], farmers' employment choices [20], and accessibility [20-22]. At the landscape scale, land price and the distance to urban areas and roads are the important predictive variables for the amount of farmland converted to forest [23]. At the regional scale, socio-economic factors become important driving variables [24]. Certain researchers have used socio-ecological models to explore the drivers of farmland abandonment caused by collective behavior [25]. Due to the complexity and scale dependence of farmland abandonment, efforts to explore the drivers of farmland abandonment must consider the many socio-economic and natural factors [26-28].

In China, the migration of the labor force from rural to urban areas and the decrease in the total agricultural labor force over the past several decades have been well documented [29,30]. A larger number of agricultural laborers currently participate in the non-farm employment, and this shift has become one of the main factors affecting agricultural land use change [10]. This phenomenon is especially noticeable in the economically lagging regions of Central West China. The increasing opportunities in other sectors (secondary and tertiary) are the main causes of increased opportunity costs associated to farming [31,32]. Although farmland abandonment may be caused by the rising relative production costs in the certain regions, there are other driving forces of farmland abandonment in the other regions of China [33,34]. In China, this spatially varying farmland abandonment pattern is poorly understood [34].

This study focuses on gaining an understanding of farmland abandonment in the Jiangxi province of China using a spatially explicitly regression model that describes the dynamical economic drivers of agricultural land use change. The model is based on agricultural land rent theory, logistical regression statistical methods, and Geographic Information System (GIS). Land rent theory, a key theory in land economics, has been commonly applied to explain the main motivation for how and why people use 
land resources and assess land values. Based on this theory, the main hypothesis in this study is that farmland abandonment at different spatial scales can be explained by land rent theory [10]. When land rent is zero or negative, the probability of farmland abandonment is much higher. Specifically, the objectives of our study are to (1) test the hypothesis that farmland abandonment takes place in locations where the agricultural cultivation costs are high and the yield potential is low, (2) explore to what extent this spatially explicit economical model is able to distinguish between the main drivers that influence farmland abandonment in the study area, (3) identify the important driving forces of farmland abandonment, and (4) and propose appropriate policy implications.

\section{Materials and Methods}

\subsection{Study Area}

The study area $\left(24^{\circ} 7^{\prime} \mathrm{N}-29^{\circ} 9^{\prime} \mathrm{N}, 114^{\circ} 02^{\prime} \mathrm{E}-118^{\circ} 28^{\prime} \mathrm{E}\right)$ is the Jiangxi province, which is located in the southern region of China and covers an area of approximately $166,000 \mathrm{~km}^{2}$ (Figure 1). This area belongs to a subtropical zone with a humid monsoon climate, an annual average temperature of $16-18{ }^{\circ} \mathrm{C}$ and an annual average rainfall of 1300-2000 mm. Due to its terrain is narrow and long, there are large differences between the climate in the southern region and that in the northern region of the study area. The annual average Sunshine is $1473.3-2077.5 \mathrm{~h}$, and the total radiation amount is $97-114.5 \mathrm{kcal} / \mathrm{cm}^{2}$. The study area is surrounded by three mountains with a chain of undulating hills located in the middle portion. Based on the digital elevation model, $54 \%$ of the study area is located at elevations $<200 \mathrm{~m}$, $33 \%$ at $200-500 \mathrm{~m}$, and $23 \%$ at $>500 \mathrm{~m}$. The soils are predominantly red soil, yellow soil, and hydromorphic paddy soil. The main vegetation types include subtropical evergreen broadleaf forest, coniferous forest, and broadleaf mixed forests. The main crops in the Jiangxi province include rice, wheat, soybeans, and sweet potatoes. In 2010, the crop planting area covered $3 \times 10^{6}$ ha, and the study area had a population of 44.56 million and a food productivity of $4.00 \times 10^{7} \mathrm{t}$. Recently, many people in the study area have participated in non-farm employment due to the development of urbanization and industrialization, and farmland abandonment has become a common phenomenon in the mountainous areas.

\subsection{Data}

\subsubsection{Land Use Data}

Land use data in this study were derived from the Data Center for Resources and Environmental Sciences of the Chinese Academy of Sciences [35], which has conducted the successive monitoring at intervals, every five years, since the late 1980s (henceforth referred to as 1990, 1995, and 2005). The land use types were divided into six classes and 24 subclasses (see Table 1). The roles of land use data include two aspects. One is used to map for farmland abandonment during the time periods 1990-1995 and 1995-2005, the other is used to calculate the related variables "distance to forests", "distance to village", etc. In this study, a conversion from farmland to grassland is considered as the abandoned areas. 
Figure 1. Location map of the Jiangxi Province in China.

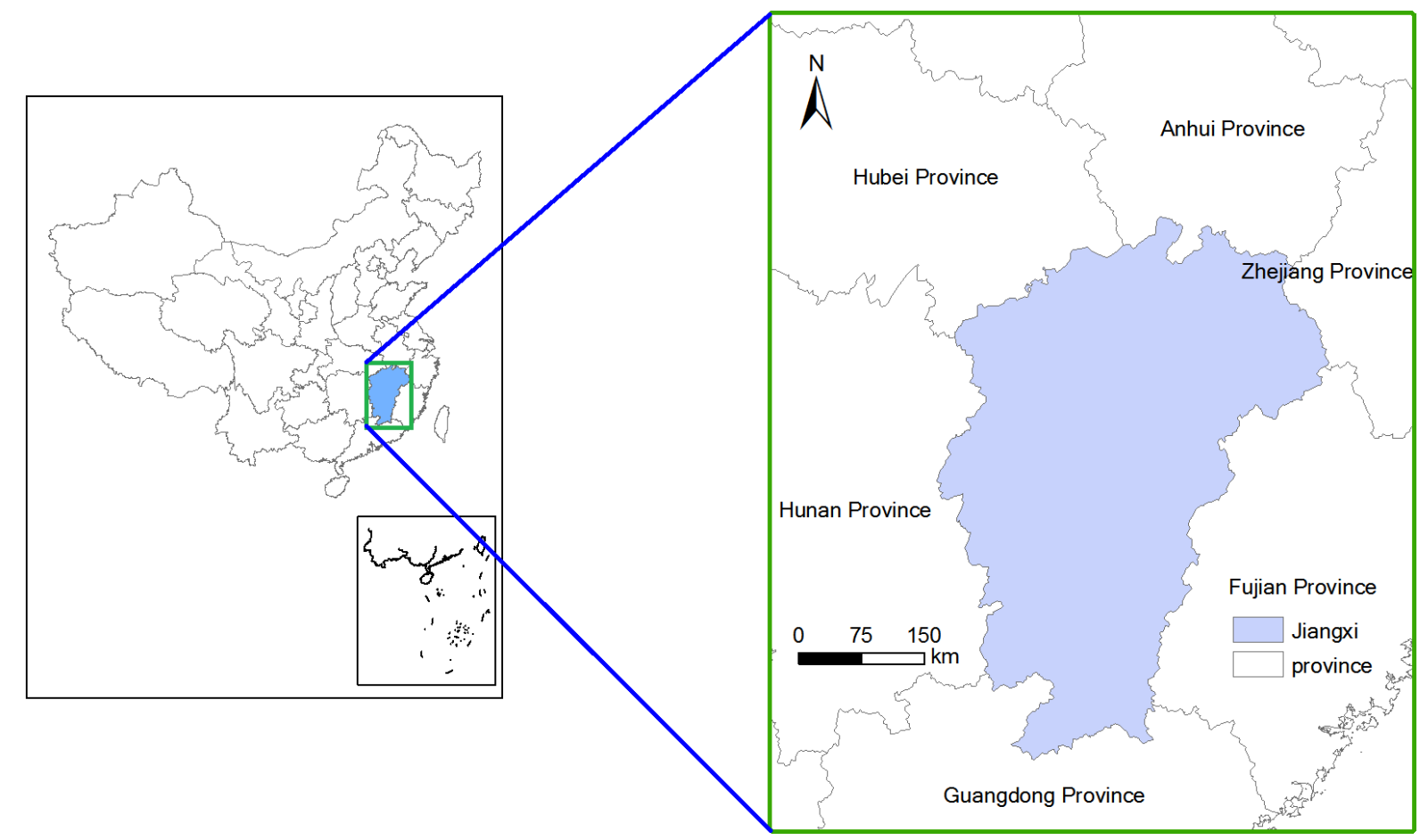

Table 1. Land use and land cover of the study area.

\begin{tabular}{|c|c|}
\hline Land use/land cover class & Land use/land cover subclass \\
\hline \multirow{2}{*}{ Farmland } & Paddy field \\
\hline & Dry field \\
\hline \multirow{3}{*}{ Forest } & Woodland \\
\hline & Shrubland \\
\hline & Open woodland \\
\hline \multirow{3}{*}{ Grassland } & High covered grass \\
\hline & Medium covered grass \\
\hline & Low covered grass \\
\hline \multirow{6}{*}{ Water area } & River and trench \\
\hline & Lake \\
\hline & Reservoir \\
\hline & Permanent glacier \\
\hline & Beach \\
\hline & Bottomland \\
\hline \multirow{3}{*}{ Built areas } & City or town region \\
\hline & Village residential area \\
\hline & Rest construct land \\
\hline \multirow{7}{*}{ Other covers } & Sand land \\
\hline & Gobi \\
\hline & Salted land \\
\hline & Swamp \\
\hline & Bare ground \\
\hline & Bare rock \\
\hline & Rest of used land \\
\hline
\end{tabular}


The spatial patterns of farmland changes during two periods (1990-1995 and 1995-2005) are shown in Figure 2. From Figure 2, we observe that farmland change was particularly widespread in the hilly areas of the Jiangxi province over the total time period.

Figure 2. Observed farmland change of two periods in the study area.

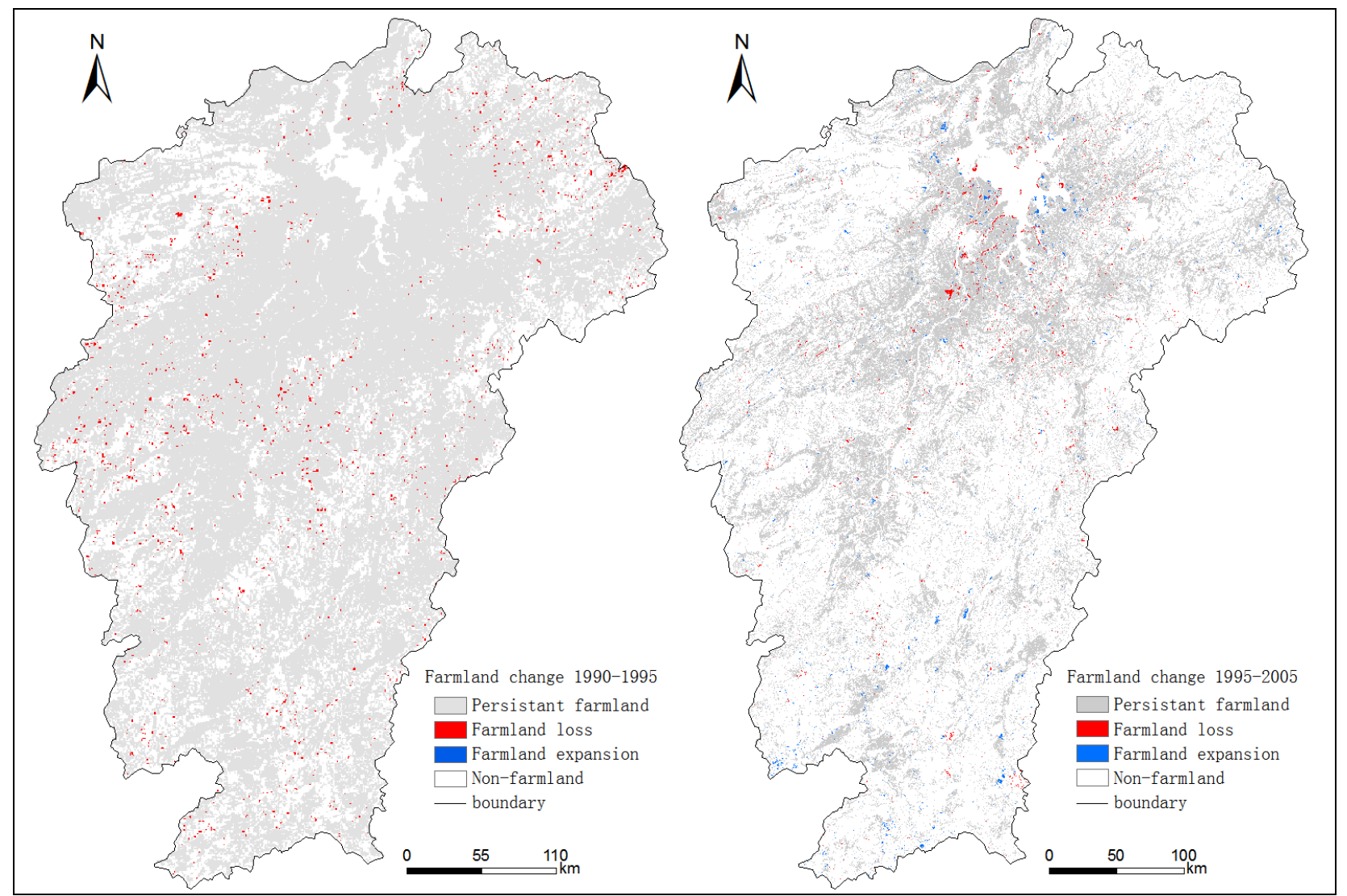

\subsubsection{Data of Biophysical Variables}

Climate, topopgraphy, and soil are considered as the main natural influencing factors that influence farmland abandonment due to differences in agricultural production conditions. Climatic data were derived from the China Meteorological Data Sharing Service System [36]. Based on the long-term observed data from 586 meteorological stations for the daily mean temperature and precipitation from 1961 to 2010, in China, a spatial distribution map of the mean annual accumulative temperature above $10{ }^{\circ} \mathrm{C}$ and precipitation were obtained using the kriging method of spatial interpolation in the software ArcGIS v. 9.3 [37].

The main topographical factors that influence farm production are slope and altitude [17]. The DEM data with a spatial resolution of $90 \mathrm{~m} \times 90 \mathrm{~m}$ from the Data Center for Resources and Environmental Sciences of Chinese Academy of Sciences were acquired, and were resampled at a spatial resolution of $100 \mathrm{~m} \times 100 \mathrm{~m}$. The soil data in the study were derived from the Second National Soil Survey of China, and the related physicochemical properties and types of soil from the database were collected and analyzed by the Institute of Soil Science at the Chinese Academy of Sciences. 


\subsubsection{Socio-Economical Data}

Socio-economical data at the county level were derived from the Jiangxi statistics yearbook from 1990 to 2006 [35,38]. The socio-economical data from 90 counties in the study area include the total population, rural population, total employees and employees in the primary sector, net income of farm per capita, size of the rural labor force, Gross Domestic Product, and secondary sector output value.

\subsection{Methods}

\subsubsection{Spatial Economical Model}

The farmer's choice of agricultural practice on the farmland is determined by the maximization of net income [39]. Land use transition occurs when the net income from the land is zero or negative [10]. In other words, the farmland abandonment phenomenon may be explained by the agricultural land rent theory from economics. The formula for the net income of farmland is expressed as follows [40]:

$$
R=p y-w l-q k-c-v d
$$

where $y$ is the yield of agricultural products, $p$ is the price of agricultural products, $l$ is the size of labor required per ha, $w$ is the corresponding labor wage, $k$ is the capital required per ha, $q$ is the annual costs of capital input, $c$ is the cost of enforcing property rights, $d$ is the distance to the central market, and $v$ is the transportation cost for the agricultural products.

If $R$ is zero or negative, farmland no longer has agricultural use value and is marginalized. The farmer's agricultural practice on the marginal land will halt because of the lack of land rent's net income. Therefore, the dependent variable in the spatial economical model for farmland abandonment is defined by $R^{*}$.

$$
R^{*}=\left\{\begin{array}{lll}
0 & \text { if } & R>0 \\
1 & \text { if } & R<=0
\end{array}\right.
$$

where $R^{*}$ is the proxy for farmland abandonment, and $R$ is the agricultural land rent. If the agricultural land rent is zero or negative, the farmland will be abandoned; otherwise it will be maintained.

According to the above formula, the main determinants of farmland abandonment include the yield of agricultural products, price of agricultural products, wage of agricultural labor, capital, cost of enforcing land property rights, transportation cost, etc. Considering the accessibility of data and the spatial characteristics of model, 20 potential determinants of farmland abandonment were initially considered in the spatially explicitly economic model of this study (see Table 2).

The yield of agricultural products $(y)$ is primarily determined by the agro-ecological conditions, technology progress and land use intensification. As the related decision parameters of technology progress and land use intensification are difficult to be estimated in the study area, these two factors were not considered in the spatially explicit economic model. The factors for agro-ecological conditions mainly include topography, soil quality, rainfall, and temperature, among others. Therefore, this study used seven variables, i.e., accumulative temperature above 10 degree, annual precipitation, distance to forest edge, soil depth, contents of soil coarse sand, slope, and elevation, to represent the potential farmland yield. When the daily mean temperature is above $10{ }^{\circ} \mathrm{C}$, most of crops begin to grow. The indicator accumulative temperature above 10 degree is an important indication index that indicates the 
potential farmland yield. The variable distance to forest edge usually has an effect on the climatic conditions of farmland. Generally, the smaller the distance to the forest edge, the greater the influence on the farmland. Farmland close to forest edges has, in general, less favorable growing and cultivation conditions than farmland remote from forest edges (due to shade, woody plant seed rain, etc.) [20]. In this study, soil depth and content of soil coarse sand represent the soil quality status. The thinner the soil depth and the higher the content of soil coarse sand, the worse the farmland quality will be. Slope not only has an effect on production of farmland, but also affects the cost of cultivation [20].

Table 2. Independent variables used in the study.

\begin{tabular}{|c|c|c|}
\hline Variable Description & Spatial Resolution & Expected Sign * \\
\hline \multicolumn{3}{|l|}{ Yield of agricultural product(y)-related variables } \\
\hline Cumulative temperature above $10^{\circ} \mathrm{C}\left(\right.$ day $\left.\times{ }^{\circ} \mathrm{C}\right)$ & $100 \mathrm{~m}$ & - \\
\hline Annual precipitation (mm/year) & $100 \mathrm{~m}$ & - \\
\hline Distance to forest edge $(\mathrm{m})$ & $100 \mathrm{~m}$ & - \\
\hline Soil depth $(\mathrm{cm})$ & $100 \mathrm{~m}$ & - \\
\hline Content of soil coarse sand (\%) & $100 \mathrm{~m}$ & + \\
\hline Slope $\left({ }^{\circ}\right)$ & $100 \mathrm{~m}$ & + \\
\hline Elevation (m) & $100 \mathrm{~m}$ & + \\
\hline \multicolumn{3}{|l|}{ Wage of agricultural labor( $w)$-related variables } \\
\hline Proportion of employees in the primary sector (\%) & County & - \\
\hline Rural labor force participation rate (\%) & County & - \\
\hline Rate of change of rural labor (\%/year) & County & - \\
\hline Rate of population urbanization (\%) & County & + \\
\hline Proportion of secondary sector's output value (\%) & County & + \\
\hline GDP per capita ( $¥ /$ capita) & County & + \\
\hline \multicolumn{3}{|l|}{ Transportation $\operatorname{cost}(v)$-related variables } \\
\hline Distance to central town $(\mathrm{m})$ & $100 \mathrm{~m}$ & - \\
\hline Distance to village $(\mathrm{m})$ & $100 \mathrm{~m}$ & - \\
\hline Distance to primary road $(\mathrm{m})$ & $100 \mathrm{~m}$ & - \\
\hline \multicolumn{3}{|l|}{ Structural characteristics in agriculture } \\
\hline Net income of farmer per capita ( $¥ /$ capita) & County & $?$ \\
\hline Average agricultural area per farmer (ha/farm) & County & + \\
\hline Rate of change of farmer (\%/year) & County & $?$ \\
\hline Rate of change of employees in the primary sector (\%/year) & County & $?$ \\
\hline
\end{tabular}

Based on the Formulas (1) and (2), the wage of farming labor variables (w) are other important determinants of farmland abandonment. The wage of farming labor is primarily determined by off-farm employment opportunities, migration, and economic development [40]. The lower the proportion of employees in the primary sector, the smaller the agricultural labor supply will be, which increases the wage for agricultural labor. The variable rural labor force participation rate in Table 2 represents the proportion of the rural labor force participation in the primary sector. The variable rate of change of rural labor indicates the proportion of the number of rural labor force change during the time period 1990-1995 or 1995-2005 in this study. The two variables rural labor force participation 
rate and rate of change of rural labor can be used a proxy for the supply condition of farming labor in this study. With the rapid development of population urbanization and industrialization, a larger proportion of the rural populations have begun to migrate from rural to urban areas because urban areas provides additional off-farm employment opportunities for rural labor. Therefore, the opportunity cost of farming labor increases, which may decrease agricultural profitability and farmland rent. Farmlands with poor quality, e.g., steeply sloped land and degraded land, will be marginalized and subsequently abandoned. The process of farmland abandonment due to population urbanization and industrialization can be explained by Figure 3.

Figure 3. Process of farmland abandonment induced by population urbanization and industrialization.

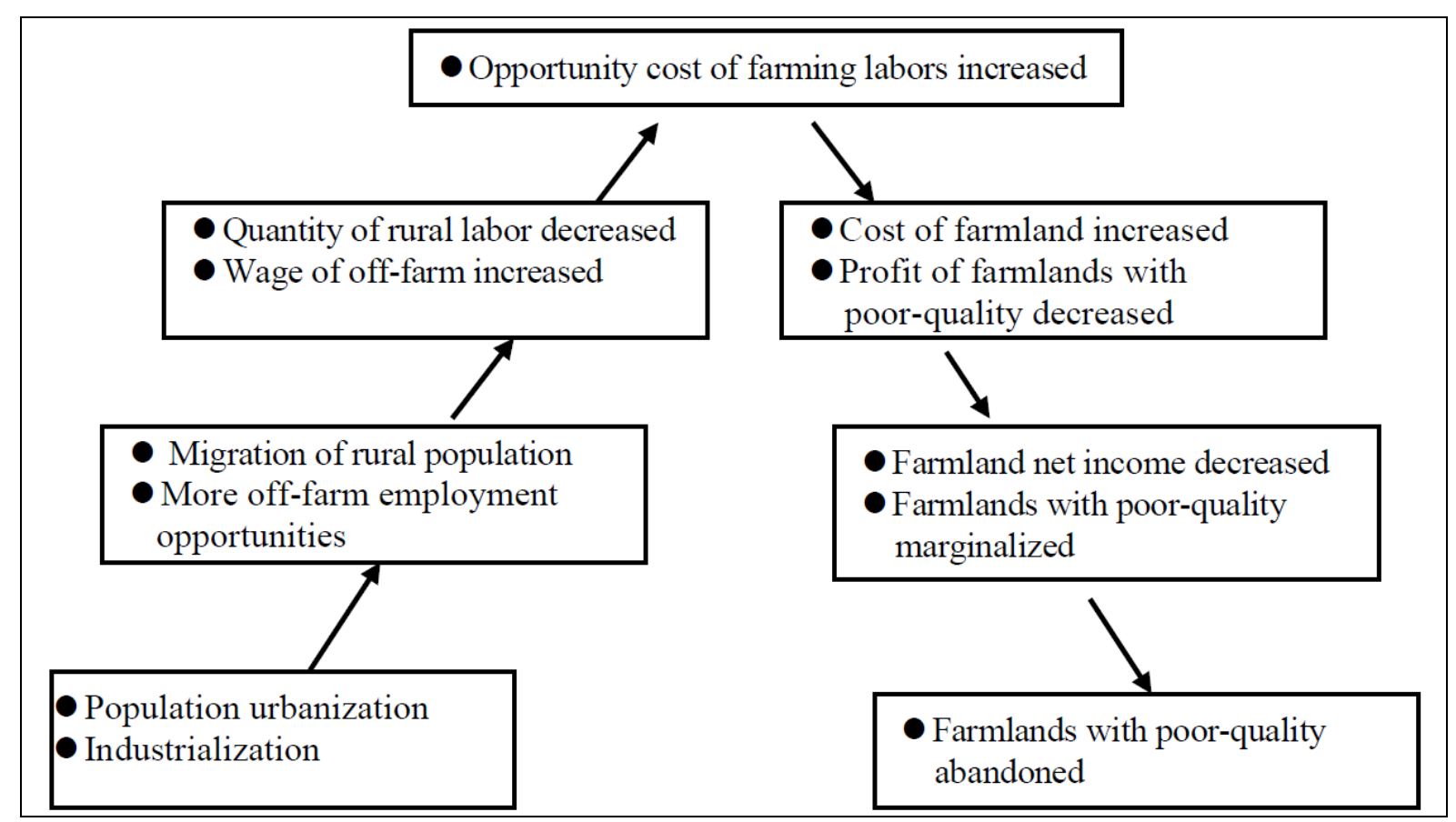

From Figure 3, we observe that population urbanization and industrialization are the indirect motivation for farmland abandonment. Therefore, six variables, i.e., proportion of employees in the primary sector, rural labor force participation rate, rate of change of rural labor force, rate of population urbanization, proportion of secondary sector's value, and GDP per capita, are selected to represent as the status of labor wages (Table 2). Among these, the variable GDP per capita is a proxy for the economic development level in different counties and the variable proportion of secondary sector's value is proposed to express the level of industrialization.

According to the agricultural land rent theory, the transportation cost of agricultural products $(v)$ is another important factor that influences farmland profit. The transportation cost of agricultural products is primarily determined by roads (extent and quality) and general infrastructure. The closer to the village, central town and roads, the lower the transportation cost will be. Three variables, i.e., distance to town, distance to village, and distance to primary road, are selected to represent the levels of transportation cost (Table 2). The farther the distance of agricultural land from villages, the more time farmers will spend in cultivation. For the agricultural products in the study area, the cost of transportation to towns is important. 
For the other determinants in the land rent equation, price of agricultural products $(p)$ depends on the market supply and demand, the number of labor and capital required per $h a(l, k)$ are mainly determined by the technologies applied, the annual costs of capital input ( $q$ ) relies on access to credit and interest rates and the cost of enforcing property rights $(c)$ depend on the property regime and land competition, these items are not be considered in this study because of they have no spatial difference and because of difficulties in quantification.

Structural variables were included in the analysis model, not for hypothesis testing, but, rather, to obtain additional information on their relationships to farmland abandonment.

\subsubsection{Multivariate Logistic Regression Model}

The linear regression model is popular in analytical studies, but it is constrained under many situations, especially if the dependent variable is a categorical variable rather than a continuous variable. On the contrary, the logistic regression model is able to address this problem properly. Multivariate logistical regression models generate regression coefficients that are calculated using certain weighted methods that explain the probability of land use change. Thus far, multivariate logistic regression models have been used to study wildlife habitats [41,42], forest fire prediction [43], and ecological land changes [44], land use changes [45-48].

Multivariate logistic regression can determine the effects and strengths of independent variables $x_{k i}$ in predicting the probability of having $p_{i}$. If we assume that $x$ is the response variable and $p$ is the response probability, then the regression model is:

$$
\ln \left(\frac{p_{i}}{1-p_{i}}\right)=\alpha+\sum_{k=1}^{k} \beta_{k} x_{k i}
$$

where $p_{i}=P\left(y_{i}=1 \mid x_{1 i}, x_{2 i}, \cdots, x_{k i}\right)$ is the occurrence probability of farmland abandonment when given $x_{1 i}, x_{2 i}, \cdots, x_{k i}, \alpha$ is the intercept and $\beta$ is the slope.

The probability of an event is a nonlinear function constructed by the independent variables and can be expressed as shown:

$$
p=\frac{\exp \left(\alpha+\beta_{1} X_{1}+\beta_{2} X_{2}+\cdots+\beta_{n} X_{n}\right.}{1+\exp \left(\alpha+\beta_{1} X_{1}+\beta_{2} X_{2}+\cdots \beta_{n} X_{n}\right)}
$$

The odds ratio is used to explain the logistic regression coefficients of the independent variables [40]. In a logistic regression model, it is more feasible to use the odds ratio to understand the event probability of independent variables because the odds ratio contains certain properties for estimating relevance [49]. We can estimate the odds ratio using the following expression [44,50]:

$$
\operatorname{odd}(p)=\exp \left(\alpha+\beta_{1} X_{1}+\beta_{2} X_{2}+\cdots+\beta_{n} X_{n}\right)
$$

In this study, we use SPSS [51] to construct the multivariate logistic regression model and evaluate the prediction power of the logistic regression model using maximum likelihood estimation (MLE), which includes the regression coefficients, standard deviation, estimated Wald $\chi^{2}$, and significance of coefficients. A positive coefficient value means that the odds ratio will increase for a unit increase of the independent variable and vice versa. Whenever the relationship among data can be estimated from a parametric model, the Wald test can be used to test the true value of the parameter [52]. Once we 
have estimated the model, we must to evaluate this model to assess how and to what extent it is able to describe the dependent variables and data effectively. If we increase the number of independent variables (especially after the continuous independent variables are included in the model), Pearson's $\chi^{2}$ and Deviation D should not be used to estimate MLE. The Akaike information criterion (AIC) statistic becomes a more useful MLE for estimating logistic regression models with continuous independent variables. Therefore, in this study we use the AIC statistic to estimate the MLE of farmland abandonment in the logistic regression model. The $A I C$ is defined as [53]:

$$
A I C=\left(\frac{-2 L \hat{L}_{s}+2(K+S)}{n}\right)
$$

where $K$ is the number of independent variables, $S$ is the number of dependent variables minus one, $n$ is the number of observations, and $L \hat{L}_{s}$ is the natural logarithm of the maximum likelihood value. The range of $-2 L \hat{L}_{s}$ is $[0,+\infty]$. The smaller the $A I C$ value is, the better the model will be fitted [50].

The goodness-of-fit of the logistic regression model of farmland abandonment can be evaluated using the percent of observations that are predicted correctly (PC), Cohen's kappa, and the area under the curve (AUC) of the receiver-operating characteristic. The PC method focuses attention on the ratio of correctly predicted cells from the total number of cells, and Cohen's kappa evaluates the accuracy of location. The indicator AUC is used to measure the performance of the model compared with that of a random model in which the cut-off threshold is varied from zero to one $[21,54,55]$. The AUC values close to 1.0 indicate a high similarity between the observed and predicted values.

To estimate the model, we combine a stepwise selection method and a conceptual model approach. We first choose the independent variables from the conceptual models and use stepwise regression to select the main independent variables before applying the saturated model to analyze which variables contribute to the farmland abandonment.

The prediction maps for farmland abandonment were generated by applying the constructed logistic models from the sampled data to the full dataset and calculating the predicted probabilities in the entire study area. According to the predicted probabilities, a common threshold of $50 \%$ is used to judge whether farmland is present or absent [21]. In other words, all probabilities higher than 50\% were predicted as "presence of farmland abandonment" and all probabilities below this threshold were labeled as "predicted absence of farmland abandonment".

\subsubsection{Sampling}

To adopt a logistic model, we use stratified random sampling to select $\mathrm{n}$ observations that are normally distributed. The use of stratified random sampling is intended to avoid spatial autocorrelation. For every observation, we record the value of each dependent and independent variable. In every model, we take 1000 observations and ensure that 0 and 1 have been observed equally for the dependent variables. Unequal numbers of 0 and 1 observations will not affect the coefficient estimation but will affect the constants [44,50]. This is because the constant is estimated by $\left(\ln p_{1}-\ln p_{2}\right)$ where $\mathrm{p}_{1}$ and $\mathrm{p}_{2}$ are frequencies of 0 and 1 of the dependent variables [56]. 


\section{Results}

To avoid high multi-collinearity among the explanatory variables, we also should remove the variables that have pair-wise correlation coefficients higher than the threshold value of 0.8 [57]. As the Pearson correlation coefficients is 0.854 between rate of urbanization and GDP per capita and 0.882 between rate of change of rural labor and rate of change of farmer in the first period model, the two variables GDP per capita and rate of change of farmer were removed from the logistic model. Therefore, 18 independent variables were ultimately included in the logistic model in the first period. As these same Pearson correlation coefficients are between 0.002 and 0.737 in the second period model, all of the independent variables were included in the logistic model in the second period.

Figure 4 shows the frequency of observation values along the gradients of slope, elevation and distance to town in the first period. The frequency of abandoned farmland (presence) is higher than that of maintained agriculture (absence) at slopes between 10 degrees and 30 degrees, at elevations above $400 \mathrm{~m}$ and at distances to town of more than 10,000 $\mathrm{m}$ in the first period (1990-1995) (see Figure 4). From Figure 4, we conclude that the variables slope, elevation, and distance to town have an obviously negative relationship with farmland abandonment from 1990 to 1995 in the study area.

Figure 4. Frequency of observations in areas where agriculture has been maintained (absence) and where farmland abandonment has been observed (presence) along the slope, elevation and distance-to-town gradients in the first period (1990-1995).
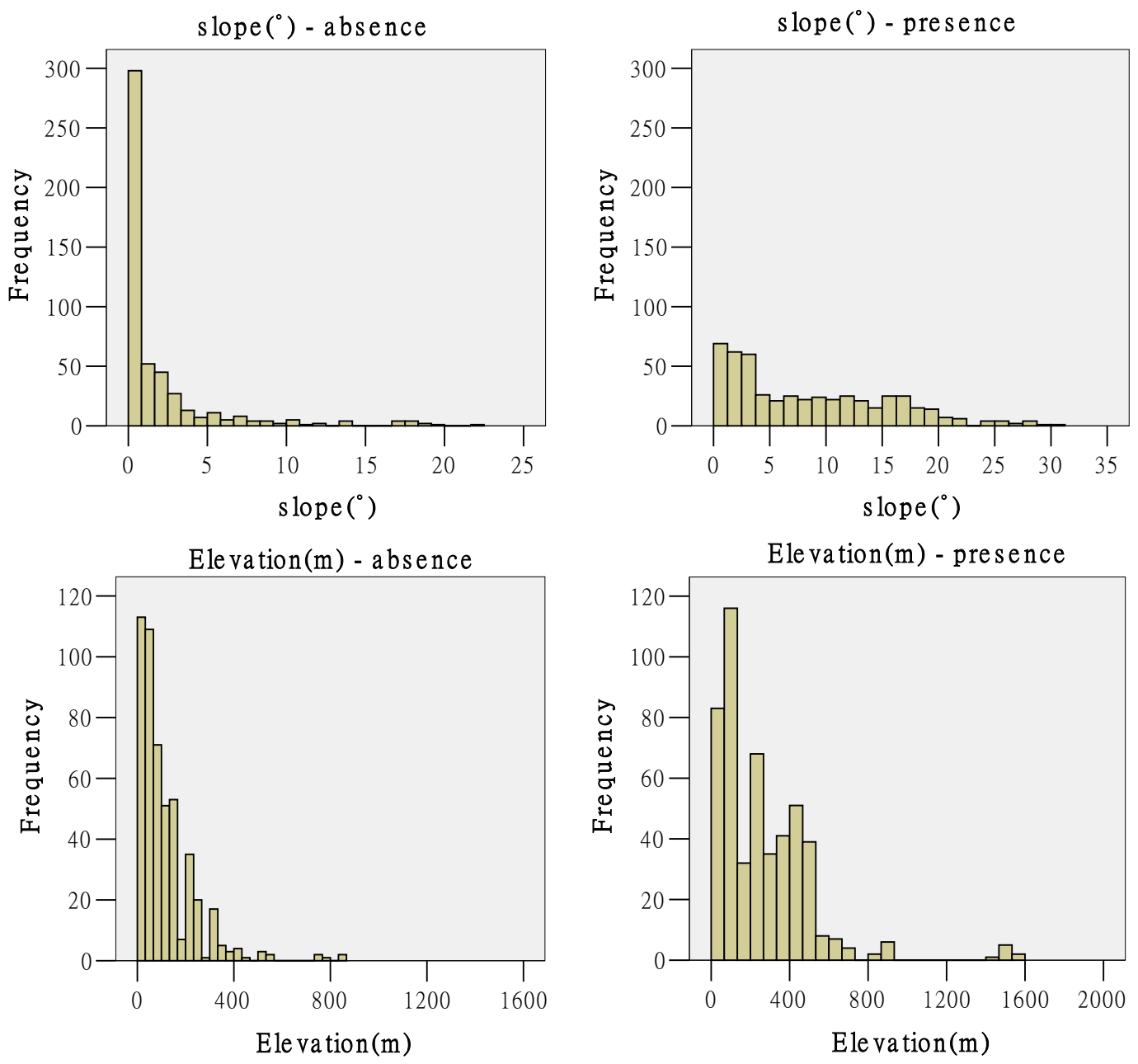
Figure 4. Cont.
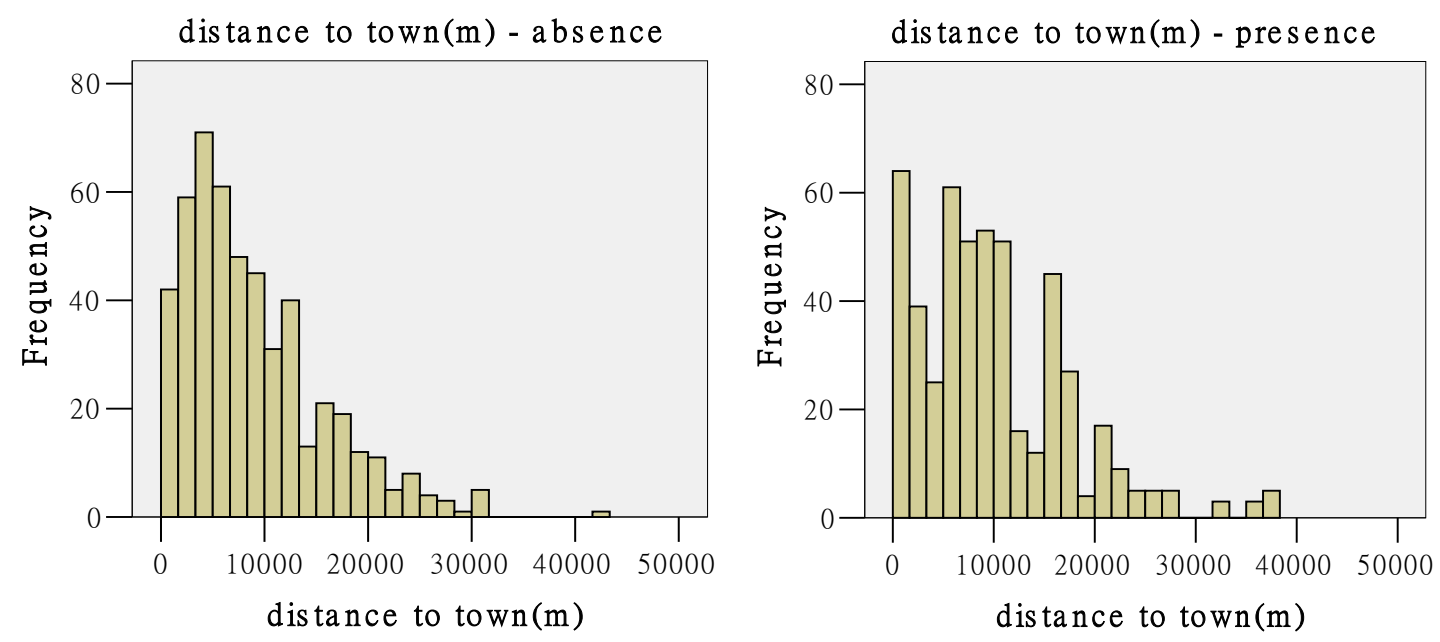

In the second period, the frequency of abandoned farmland (presence) is obviously higher than that of maintained agriculture (absence) with a distance to village of more than $8000 \mathrm{~m}$, at slopes above 10 degrees and cumulative temperature above 10 degrees between 7500 and $8000{ }^{\circ} \mathrm{C}(1995-2005)$ (see Figure 5). From Figure 5, we conclude that the variables distance to village, slope, and accumulative temperature above 10 degrees have significantly negative relationships with farmland abandonment from 1995 to 2005 in the study area.

Figure 5. Frequency of observations in locations where agriculture has been maintained (absence) and where farmland abandonment has been observed (presence) along the slope, distance-to-village and cumulative-temperatures-above-10-degrees gradients in the second period (1995-2005).
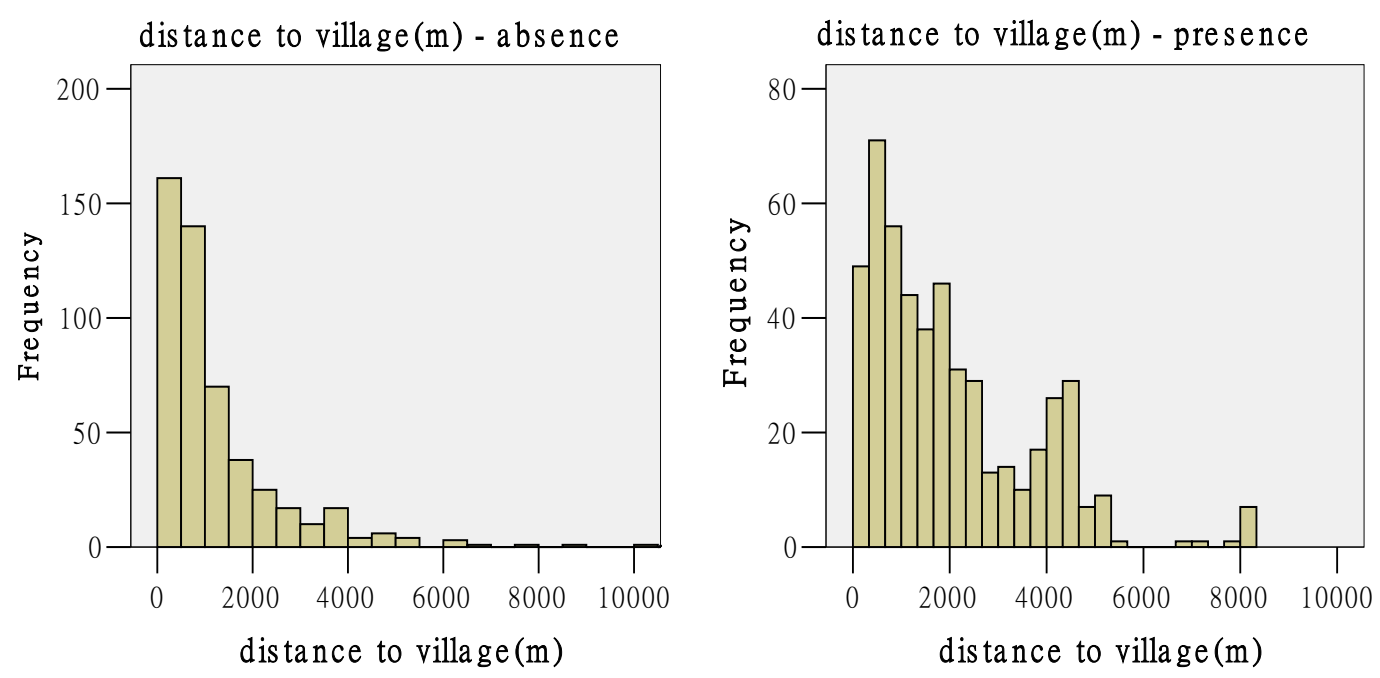
Figure 5. Cont.
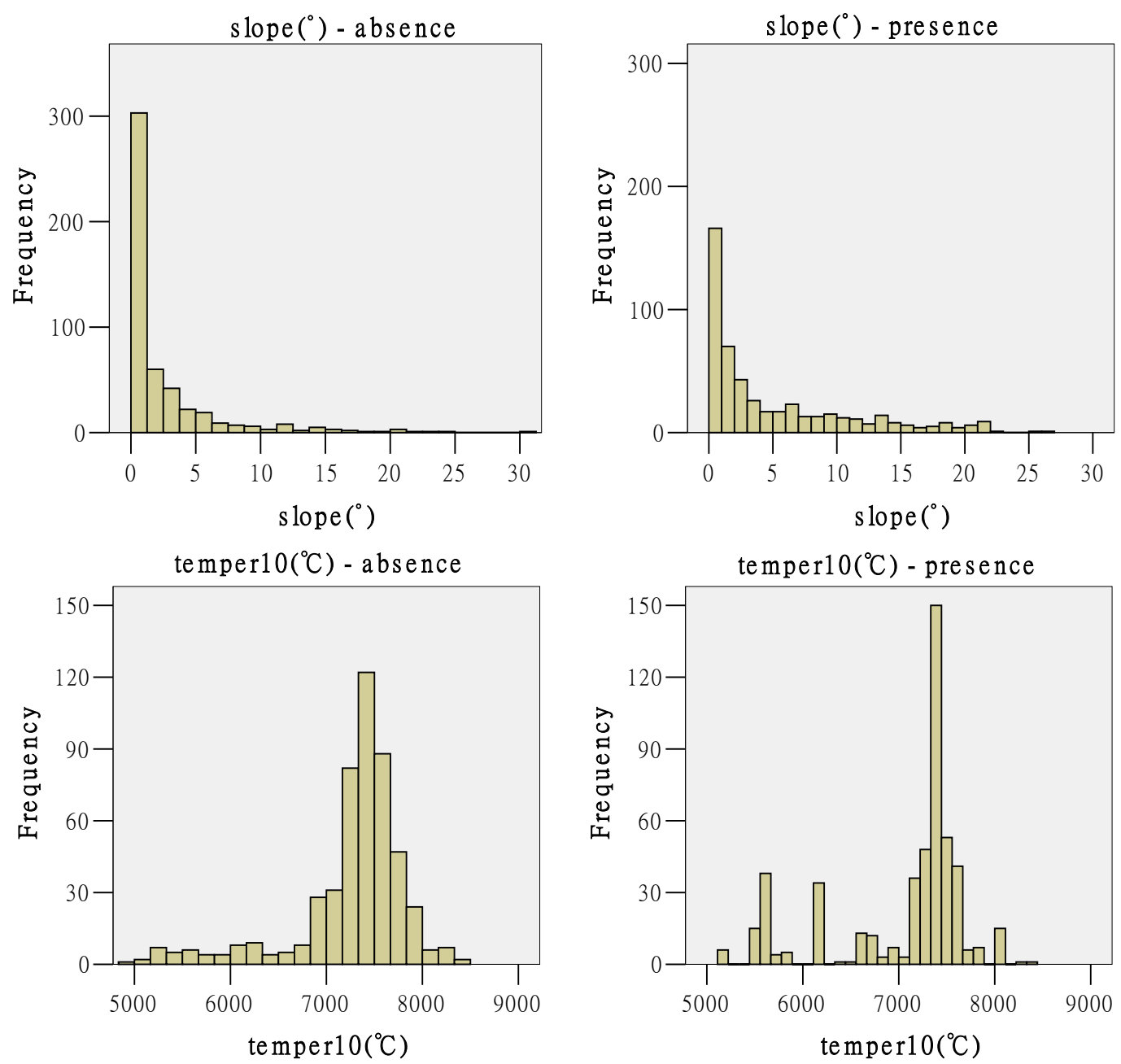

As shown by the Wald-Chi-square tests (Table 3), the prediction model of farmland abandonment is statistically highly significant $(p<0.001)$ in the first period. According to the related reference [50], the value of Wald's $\chi^{2}$ can be used to judge the importance of independent variables. The more the value of Wald's $\chi^{2}$ for an independent variable, the more important the independent variable is. The results from the spatially explicit logistic regressions for farmland abandonment in the first period indicate that topographic characteristics, level of population urbanization, status of rural labor supply and market accessibility are the most important spatial determinants of farmland abandonment (Table 3). For example, farmland abandonment was more likely on steeper slopes and at higher elevation. The odds ratio for slope is 1.22 , which means that an additional slope degree rendered abandonment $22 \%$ more likely. For every $100 \mathrm{~m}$ of altitude, the risk of abandonment increased by $3 \%$ at the $1 \%$ significance level. Content of soil coarse sand has a strong positive bearing on abandonment, and an additional percentage point increased abandonment by $6 \%$ at the $0.1 \%$ significance level. Another important independent variable in the first period is rate of urbanization and the result shows that population urbanization and economic development increased the likelihood of farmland abandonment. The variable Distance to town is positively related to abandonment at the $0.1 \%$ significance level, which shows that farmland abandonment was more likely with increasing distance to town. The rate of change of rural labor decreased abandonment by $9 \%$ at the $5 \%$ significance level. 
Table 3. Final prediction model of farmland abandonment based on sampling observations in the first period (1990-1995) (Observation: $\mathrm{n}=1000)$.

\begin{tabular}{|c|c|c|c|c|c|}
\hline Variables & $\begin{array}{c}\text { Estimator } \\
(\boldsymbol{\beta})\end{array}$ & $\begin{array}{c}\text { Standard } \\
\text { Error (SE) }\end{array}$ & $\begin{array}{c}\text { Wald } \chi^{2} \\
\text { Statistics }\end{array}$ & $p$ Value & $\operatorname{EXP}(\beta)$ \\
\hline \multicolumn{6}{|l|}{ Wald-Chi-square: $523.987(p<0.0001)$} \\
\hline Constant & 21.209 & 5.887 & 12.981 & 0.000 & $2 \times 10^{9}$ \\
\hline Cumulative temperature above 10 degrees & -0.001 & 0.000 & 12.439 & $0.000^{* * *}$ & 0.999 \\
\hline Annual precipitation & -0.009 & 0.004 & 5.852 & $0.016^{*}$ & 0.991 \\
\hline Distance to forest edge & -0.001 & 0.000 & 9.273 & $0.002^{* *}$ & 0.999 \\
\hline Soil depth & -0.005 & 0.011 & 0.191 & 0.662 & 0.995 \\
\hline Content of soil coarse sand & 0.056 & 0.012 & 22.604 & $0.000^{* * *}$ & 1.058 \\
\hline Slope & 0.201 & 0.025 & 66.942 & $0.000^{* * *}$ & 1.223 \\
\hline Elevation & 0.003 & 0.001 & 8.126 & $0.004^{* *}$ & 1.003 \\
\hline Proportion of employees in the primary sector & -0.013 & 0.007 & 3.203 & 0.074 & 0.987 \\
\hline Rural labor force participation rate & -0.008 & 0.004 & 2.959 & 0.085 & 0.993 \\
\hline Rate of change of rural labor & -0.090 & 0.048 & 3.611 & $0.050^{*}$ & 0.914 \\
\hline Rate of urbanization & 0.058 & 0.009 & 41.730 & $0.000^{* * *}$ & 1.060 \\
\hline Distance to town & $7.0 \times 10^{-5}$ & 0.000 & 17.243 & $0.000^{* * *}$ & 1.000 \\
\hline Distance to village & $8.0 \times 10^{-5}$ & 0.000 & 1.476 & 0.224 & 1.000 \\
\hline Distance to primary road & $2.0 \times 10^{-5}$ & 0.000 & 1.256 & 0.262 & 1.000 \\
\hline Net income of farmer per capita & -0.003 & 0.001 & 15.816 & $0.000^{* * *}$ & 0.997 \\
\hline Average agricultural area per farm & 2.404 & 1.203 & 3.993 & $0.046^{*}$ & 11.068 \\
\hline Rate of change of employees in the primary sector & 0.059 & 0.042 & 1.931 & 0.165 & 1.060 \\
\hline
\end{tabular}

$$
* p<0.05 ; * * p<0.01 ; * * * p<0.0001 \text {. }
$$

According to the Wald-Chi-square tests (see Table 4), the prediction model of farmland abandonment in the second period is also statistically highly significant $(p<0.001)$. Based on the Wald $\chi^{2}$, distance to village, soil depth, cumulative temperature above 10 degrees, slope, rate of change of employees in the primary sector, and net income of farmer per capita are important variables for farmland abandonment in the second period (Table 4). Farmland abandonment was more likely on the poor-quality land and in the developed areas in the second period. For example, farmland abandonment was also more likely on steeper slopes in the study area. Soil depth had a strong negative effect on abandonment and an additional $1 \mathrm{~cm}$ decreased abandonment by $5 \%$ at the $0.1 \%$ significance level (see Table 4). For the additional percentage for rate of urbanization and proportion of secondary sector's value, the risk of farmland abandonment increased by $3 \%$ at the $1 \%$ significance level.

From the results of two logistic regression models, we conclude that some bio-physical and transportation cost-related variables are the relatively important determinants of farmland abandonment, i.e., slope, elevation, content of soil coarse sand, soil depth, cumulative temperature above 10 degrees, and distance to village. Slope and elevation are strongly and positively related to farmland abandonment. For soil attributes, content of soil coarse sand and soil depth show significantly negative relationships with farmland abandonment. Furthermore, the climate variable cumulative temperature above 10 degrees has a significantly negative relationship with farmland abandonment in both models (see Table 3 and Table 4). The logistic regression model in the first period shows that the variable 
annual precipitation displays a negative relationship with farmland abandonment at the $0.1 \%$ significance level (Table 3).

Table 4. Final prediction model of farmland abandonment based on sampling observations in the second period (1995-2005) (Observation: $\mathrm{n}=1000)$

\begin{tabular}{|c|c|c|c|c|c|}
\hline Variables & $\begin{array}{c}\text { Estimator } \\
(\boldsymbol{\beta}) \\
\end{array}$ & $\begin{array}{c}\text { Standard } \\
\text { Error (SE) }\end{array}$ & $\begin{array}{c}\text { Wald } \chi^{2} \\
\text { Statistics }\end{array}$ & $p$ Value & $\mathbf{E X P}(\boldsymbol{\beta})$ \\
\hline \multicolumn{6}{|l|}{ Wald-Chi-square: $210.703(p<0.0001)$} \\
\hline Constant & 12.046 & 2.372 & 25.787 & 0.000 & $1.7 \times 10^{5}$ \\
\hline Cumulative temperature above 10 degrees & -0.001 & 0.000 & 17.084 & $0.000^{* * *}$ & 0.999 \\
\hline Annual precipitation & $-1.9 \times 10^{-4}$ & 0.001 & 0.032 & 0.859 & 1.000 \\
\hline Distance to forest edge & $2.6 \times 10^{-4}$ & 0.000 & 6.556 & $0.010^{* *}$ & 1.000 \\
\hline Soil depth & -0.051 & 0.011 & 23.670 & $0.000^{* * *}$ & 0.950 \\
\hline Content of soil coarse sand & -0.027 & 0.015 & 3.168 & 0.075 & 0.973 \\
\hline Slope & 0.080 & 0.022 & 13.382 & $0.000^{* * *}$ & 1.083 \\
\hline Elevation & -0.001 & 0.001 & 1.184 & 0.277 & 0.999 \\
\hline Proportion of employees in the primary sector & -0.015 & 0.006 & 5.736 & $0.017^{*}$ & 0.985 \\
\hline Rural labor force participation rate & -0.014 & 0.005 & 8.751 & $0.003^{* *}$ & 0.986 \\
\hline Rate of change of rural labor & -1.113 & 0.724 & 2.364 & 0.124 & 0.329 \\
\hline Rate of urbanization & 0.031 & 0.011 & 7.639 & $0.006^{* *}$ & 1.032 \\
\hline Proportion of secondary sector's output value & 0.031 & 0.015 & 4.561 & $0.033^{*}$ & 1.032 \\
\hline GDP per capita & $7.1 \times 10^{-5}$ & 0.000 & 6.279 & $0.012^{*}$ & 1.000 \\
\hline Distance to town & $4.4 \times 10^{-5}$ & 0.000 & 11.315 & $0.001^{* *}$ & 1.000 \\
\hline Distance to village & $3.5 \times 10^{-5}$ & 0.000 & 26.371 & $0.000^{* * *}$ & 1.000 \\
\hline Distance to primary road & $1.5 \times 10^{-5}$ & 0.000 & 1.102 & 0.294 & 1.000 \\
\hline Net income of farmer per capita & -0.002 & 0.001 & 17.766 & $0.000^{* * *}$ & 0.998 \\
\hline Average agricultural area per farm & 2.851 & 0.909 & 9.835 & $0.002^{* *}$ & 17.297 \\
\hline Rate of change of farm & 0.263 & 0.172 & 2.330 & 0.127 & 1.301 \\
\hline Rate of change of employees in the primary sector & -2.380 & 0.618 & 14.838 & $0.000^{* * *}$ & 0.093 \\
\hline
\end{tabular}

$* p<0.05 ; * * p<0.01 ; * * * p<0.0001$.

The wages for farm labor variables are significantly related to farmland abandonment in the both model (see Tables 3 and 4). For example, the variables rural labor force participation rate and rate of change of rural labor have a negative relationship with farmland abandonment in the both models. However, there are positive relationships between the variables rate of urbanization and proportion of secondary sector's output value and farmland abandonment. Rate of change of employees in the primary sector has a strong negative effect on farmland abandonment (see Table 4). This means that the regions having fewer rates of employees in the primary sector are easier to abandon farmland due to labor shortages.

The goodness-of-fit of the two period logistic regression models was observed to differ (Table 5). The value of AUC is 0.81 for the first period logistic model and 0.70 for the second period logistic model, which is close to 1.0 and indicates a high similarity between the observed and predicted values. Compared them with the results of previous literature [20], the AUC values of the models used in this study are higher. The results of the two models of farmland abandonment for PC and Kappa were good in the two periods. According to the Formula (6), the value of AIC is 0.89 for the first period logistic 
model and 1.22 for the other. Through the value of AUC, PC and Kappa, we conclude that the goodness-of-fit of first period's logistic regression model is better than that of second period's logistic regression model.

Table 5. Goodness-of-fit of logistic regression models for farmland abandonment in two periods.

\begin{tabular}{ccccc}
\hline Model & AIC & PC & AUC & Kappa \\
\hline First period model & 0.89 & 0.81 & 0.80 & 0.45 \\
Second period model & 1.22 & 0.70 & 0.70 & 0.41 \\
\hline
\end{tabular}

\section{Discussion}

Our study shows that farmland abandonment was highly correlated with yield potential-related variables, which corroborates the results of previous studies $[17,19,20]$. The significantly positive relationship between slope and farmland abandonment suggests that farmlands with complex topographical conditions are more likely to be abandoned, primarily because the steeper the slope, the lower the yield potential. Lands with higher soil sand content and thinner soil depth are more likely to be abandoned, which also suggests that farmland is inclined to be abandoned on poor-quality land where the yield of agricultural production is lower.

The paper also shows that climate factors impacted farmland abandonment. The reason why lands with lower cumulative temperature above 10 degrees are more likely to be abandoned is that this lower vale can limit crop growth. Most of the abandoned areas consisted of dry fields with poor irrigation, where the main water supplies for agricultural practices depend on precipitation.

The wage for farming labor contributes to farmland abandonment in both models. Farmland is more likely to be abandoned in those regions with a lower rural labor force participation rate. The main reason for this result is that the lower the rural labor force participation rate, the higher the proportion of off-farm employers, which reduces the amount of farming labor supply and then increases the level of labor wage.

The reason that variable rate of change of rural labor impacts on the farmland abandonment in the study area is that the more rapidly the decrease in rural labor, the smaller the rural labor supply. Furthermore, the variable proportion of employees in the primary sector is another important determiner that shows a significantly negative relationship with farmland abandonment and drove a large amount of the rural populations to engage in non-agricultural industries, thus influencing the amount of rural labor supply. The changes in farming workforce supply and demand directly caused increased in wages for rural labor in China. For example, the average salary of peasant workers going out increased from $¥ 781$, in 2003, to $¥ 953$, in 2006, and is increasing year by year [58].

The variables rate of urbanization and proportion of secondary sector's output value have a significantly positive relationship with farmland abandonment, which indicates that farmland is more inclined to be abandoned in those areas with higher levels of population urbanization and industrialization because population urbanization and industrialization would increase the opportunity cost of farming labor. Recently, the phenomenon of a "peasant worker shortage" has become quite common in China due to rapid development of population urbanization and industrialization [33,59]. The phenomenon of a 
"peasant worker shortage" has accelerated the process of farmland abandonment $[33,59]$. The variable GDP per capita also has a positive relationship with farmland abandonment, which means that as the size of the developed areas with more highly developed economics grows, the greater the probability of farmland abandonment will be. Population urbanization and industrialization are the main drivers of farmland abandonment due to the increased wage for farming labor. Farmland is more likely to be abandoned in those areas with high off-farm employment opportunities, larger migrations, and rapid economic development.

With respect to the transportation cost of agricultural practices, the variables distance to town and distance to village have a positive relationship with farmland abandonment, which shows that farmland is more likely to be abandoned in those areas with higher transportation costs. However, the variable distance to the primary road is not significantly related to farmland abandonment in both models. It is probable that distance to rural road is an important transportation cost determiner for farmland abandonment. As data accessibility is difficult, the variable distance to rural road was not considered in this study, but from the results in the both models, we generally conclude that transportation cost-related variables have an impact on farmland abandonment. The conclusion that farmland abandonment is related to accessibility corroborates the results of previous studies [20-22].

For the determinants of the structural characteristics in agriculture, the variables net income of farmer per capita and average agricultural area per farm are also highly important for farmland abandonment in both models. There is a significantly negative relationship between the net income of farmer per capita and farmland abandonment in the two periods, which means that the lower the net income of the farmer per capita, the greater the probability that the farmer will abandon the farmland. Furthmore, the variable average agricultural area per farm has a positive relationship with farmland abandonment, which indicates that those farmers with lower net income and larger agricultural areas are more likely to abandon their farmlands. This corroborates the results of previous studies $[33,34,60]$. When studying the land abandonment in Northern Norway, Stokstad also found that the farmers with low income are easier to abandon farmland [60]. Furthermore, the size of the farm, including lease and own farmland, is an important factor on the decision of the farmers' abandoning their farmland [60]. It is probable that farmers are willing to release a portion of labor to take part in off-farm industries and improve their living standard and simultaneously demand that the basal ratio can be maintained because of a higher agricultural area per farm.

Compared the models of two time periods, we indicate that there are almost the same driving forces and consistent relationship with farmland abandonment. However, there are some differences in the important variables for the models of two periods. In the first period, the important variables are slope, rate of urbanization and content of soil coarse sand. However, the distance to village and the net income of farmer per capita are important for farmland abandonment in the second time period. This is because China's reform and opening up has made large amounts of rural laborers move into cities since the late 1990s, which increases the opportunity cost of farming labor.

These results generally proved the study hypothesis as they suggest that farmland abandonment took place in locations where the agricultural cultivation costs were high and yield potential was low. Although the important drivers differ between the two periods, the construction of two spatially explicit economic models in this study revealed the same dynamic mechanisms of farmland 
abandonment. In other words, farmland abandonment can be effectively explained by agricultural land rent theory in the study area.

Although a portion of important driving forces of farmland abandonment were identified through the land economic model in this study, the mechanisms of land use changes cannot be comprehensively and systematically reflected, if only from an economics angle [39]. In reality, many other factors influence farmland abandonment, such as the land and agricultural policies of local governments (i.e., conversion of cropland to forest and grassland project, agricultural subsidy policy, and cultivated land protection policies). For example, in the plains areas, marginalized farmland is not likely to be abandoned through intensive production and management or other drivers (i.e., land sublet to increase profits from agricultural land). Therefore, the question of how to consider the policies determinants is highly important in the spatial economic model of farmland abandonment.

Based on the perspective of "economic man", this study explored the mechanisms of farmland abandonment. While this explanation may seem appealing for the sake of simplicity, the reality is usually not as simple. On the one hand, agricultural production is very often carried out in disregard of economic profitability, simply because of not being market-oriented but, rather, aimed at the subsistence of the family. On the other hand, lack of generational succession is a common factor for farmland abandonment in developed countries, even in highly productive areas. Although the latter could be partially explained as cost of opportunity for labor, intangible aspects like prestige, public recognition, or pride of farming as a profession also play a significant role.

At the province scale, there is no spatial difference in some variables, i.e., the prices for agricultural products due to using spatial model through spatial sample. If using spatial model to study the problem farmland abandonment at the China scale, we should consider the prices of agricultural products. Although some potentially interesting variables are not included in the spatially explicit economic model to explain farmland abandonment due to due to lack of data availability or difficult quantification, some results in this study about the positive or negative correlation between farmland abandonment and some independent variables can be explained by the von Thunen model. The goodness of the model should be better if the model can be expanded by the opportunity costs and land use policies. The driving forces of farmland abandonment include economic factors, technical factors, and social factors $[10,59,61]$. In a subsequent research project, we will improve the deficiencies of the model used in this study. We should explicitly consider the different economic factors (income, production technologies), political factors (land markets, property rights), and structural environments (i.e., market structure-subsistence farming or contractors, etc.) in future analysis.

From a European perspective, there are a lot of policy measures actually in place which should prevent land abandonment on marginal sites [9]. For the problem of farmland abandonment or farmland marginalization in China, we need to consider the situation in China to propose appropriate countermeasures. Specifically, some policy implications are provided for potential future policy decisions in China. (1) In China, many forests and other poor-quality lands were exploited into farmland due to the government's policy "farmland requisition-compensation balance" [62]. Through this study, is it feasible for the poor-quality other lands exploited into farmland due to facing the problem of abandonment in future? Moreover, this process of exploitation also brings soil erosion and biodiversity loss. Therefore, we need to reassess the policy about the area balance of farmland at regional scale. In the case of the increasing role of agricultural land marginalization, too much 
emphasis on the balance of farmland's total area in China does not meet the law of economic development [61]. Moreover, technological advances in agriculture offer the possibility for the withdrawal of some farmlands [10]. Therefore, those farmlands with poor quality and location should be quitted for agricultural uses. (2) For the Grain for Green project in China, how to effectively compensate farmers should be reassessed due to farmland abandonment. (3) Some agricultural policies in China, i.e., increasing incomes and decreasing burdens in agriculture, can only alleviate or postpone the process of farmland abandonment, but not eliminate it. This requires regional and central governments to make a more positive response regarding land use mechanism.

\section{Conclusions}

The spatially explicit economic model used in this study is able to identify the main driving forces of farmland abandonment. The yield of agricultural product-related variables, i.e., slope, elevation, content of soil coarse sand, soil depth, and cumulative temperature above 10 degrees, are significantly correlated with farmland abandonment in the study area. Farmland is more inclined to be abandoned in those areas with higher levels of population urbanization and industrialization. Furthermore, the increasing opportunity cost of farming labor has become one of the motivations for farmland abandonment because of a rural labor shortage induced by the rapid development of population urbanization and industrialization. Farmlands are more likely to be abandoned in locations far from the villages and towns because of higher transportation costs. Those farmers with a lower net income and larger agricultural area are more likely to abandon poor-quality farmland. The results support the hypothesis that farmland abandonment is derived from land marginalization. In addition, this study also indicates that the spatially explicit economic model in this article can distinguish some driving forces of farmland abandonment.

\section{Acknowledgements}

We thank four anonymous reviewers for their constructive comments. This study was supported by the National Natural Science Foundation of China (No. 41361111), the Major Research Plan of National Social Science Foundation of China (No. 12\&ZD213), the Natural Science Foundation of Jiangxi Province (No. 20122BAB203025), the Social Science Foundation of Jiangxi Province (No. 13GL05 and No. 13YJ53), the China Postdoctoral Science Foundation (No. 2012M521286 and No. 2013T60647).

\section{Author Contributions}

Hualin Xie and Peng Wang had the original idea for the study. Peng Wang was responsible for data collecting. Hualin Xie and Guanrong Yao carried out the analyses. All the authors drafted the manuscript, and approved the final one.

\section{Conflicts of Interest}

The authors declare no conflict of interest. 


\section{References}

1. Li, X. Core of global environmental change research: Frontier in land use and coverage change. Acta Geogr. Sin. 1996, 51, 553-558.

2. Vitousek, P.M. Human domination of Earth's ecosystems. Science 1997, 277, 494-499.

3. Xie, H.; Wang, P.; Huang, H. Ecological risk assessment of land use change in the Poyang Lake eco-economic zone, China. Int. J. Environ. Res. Public Health 2013, 10, 328-346.

4. Izquierdo, A.E.; Grau, H.R. Agriculture adjustment, land-use transition and protected areas in Northwestern Argentina. J. Environ. Manage. 2009, 90, 858-865.

5. Arnaez, J.; Lasanta, T.; Errea, M.P.; Ortigosa, L. Land abandonment, landscape evolution, and soil erosion in a Spanish mediterranean mountain region: the case of Camero Viejo. Land Degrad. Dev. 2011, 22, 537-550.

6. Nunes, A.N.; Coelho, C.O.A.; de Almeida, A.C.; Figueiredo, A. Soil erosion and hydrological response to land abandonment in a central inland area of Portugal. Land Degrad. Dev. 2010, 21, 260-273.

7. Giupponi, C.; Ramanzin, M.; Sturaro, E.; Fuser, S. Climate and land use changes, biodiversity and agri-environmental measures in the Belluno province, Italy. Environ. Sci. Pol. 2006, 9, 163-173.

8. Hatna, E.; Bakker, M.M. Abandonment and expansion of arable land in Europe. Ecosystems 2011, $14,720-731$.

9. MacDonald, D.; Crabtree, J.R.; Wiesinger, G.; Dax, T.; Stamou, N.; Fleury, P.; Gutierrez Lazpita, J.; Gibon, A. Agricultural abandonment in mountain areas of Europe: Environmental consequences and policy response. J. Environ. Manage. 2000, 59, 47-69.

10. Li, X.; Zhao, Y. Forest transition, agricultural land marginalization and ecological restoration. China Popul. Res. Environ. 2011, 21, 91-95.

11. Zhong, T.Y.; Huang, X.J.; Zhang, X.Y.; Wang, K. Temporal and spatial variability of agricultural land loss in relation to policy and accessibility in a low hilly region of southeast China. Land Use Pol. 2011, 28, 762-769.

12. Khanal, N.R.; Watanabe, T. Abandonment of land and its consequences. Mt. Res. Dev. 2006, 26, $32-40$.

13. Weissteiner, C.J.; Boschetti, M.; Bottcher, K.; Carrara, P.; Bordogna, G.; Brivio, P.A. Spatial explicit assessment of rural land abandonment in the Mediterranean area. Glob. Planet. Change 2011, 79, 20-36.

14. Diaz, G.I.; Nahuelhual, L.; Echeverria, C.; Marin, S. Drivers of land abandonment in Southern Chile and implications for landscape planning. Landsc. Urban Plann. 2011, 99, 207-217.

15. Gibon, A.; Sheeren, D.; Monteil, C.; Ladet, S.; Balent, G. Modelling and simulating change in reforesting mountain landscapes using a social-ecological framework. Landsc. Ecol. 2010, 25, 267-285.

16. Houet, T.; Verburg, P.H.; Loveland, T.R. Monitoring and modelling landscape dynamics. Landsc. Ecol. 2010, 25, 163-167.

17. Mottet, A.; Ladet, S.; Coque, N.; Gibon, A. Agricultural land-use change and its drivers in mountain landscapes: A case study in the Pyrenees. Agric. Ecosyst. Environ. 2006, 114, 296-310. 
18. Bakker, M.M.; Govers, G.; Kosmas, C.; Vanacker, V.; van Oost, K.; Rounsevell, M. Soil erosion as a driver of land-use change. Agric. Ecosyst. Environ. 2005, 105, 467-481.

19. Gisbert, J.M.; Ibanez, S.; Perez, M.A. Terrace abandonment in the Ceta Valley, Alicante Province, Spain. Adv. Geo. Ecol. 2005, 36, 329-337.

20. Gellrich, M.; Baur, P.; Koch, B.; Zimmermann, N.E. Agricultural land abandonment and natural forest re-growth in the Swiss mountains: A spatially explicit economic analysis. Agric. Ecosyst. Environ. 2007, 118, 93-108.

21. Lakes, T.; Muller, D.; Kruger, C. Cropland change in southern Romania: A comparison of logistic regressions and artificial neural networks. Landsc. Ecol. 2009, 24, 1195-1206.

22. Nagendra, H.; Southworth, J.; Tucker, C. Accessibility as a determinant of landscape transformation in western Honduras: linking pattern and process. Landsc. Ecol. 2003, 18, 141-158.

23. Crk, T.; Uriarte, M.; Corsi, F.; Flynn, D. Forest recovery in a tropical landscape: What is the relative importance of biophysical, socioeconomic, and landscape variables? Landsc. Ecol. 2009, 24, 629-642.

24. Cocca, G.; Sturaro, E.; Gallo, L.; Ramanzin, M. Is the abandonment of traditional livestock farming systems the main driver of mountain landscape change in Alpine areas? Land Use Pol. 2012, 29, 878-886.

25. Figueiredo, J.; Pereira, H.M. Regime shifts in a socio-ecological model of farmland abandonment. Landsc. Ecol. 2011, 26, 737-749.

26. Corbelle-Rico, E.; Crecente-Maseda, R.; Sante-Riveira, I. Multi-scale assessment and spatial modelling of agricultural land abandonment in a European peripheral region: Galicia (Spain), 1956-2004. Land Use Pol. 2012, 29, 493-501.

27. Lambin, E.F.; Meyfroidt, P. Land use transitions: Socio-ecological feedback versus socio-economic change. Land Use Pol. 2010, 27, 108-118.

28. Lambin, E.F.; Turner, B.L.; Geist, H. Our Emerging understanding of the causes of land use and cover change. Glob. Environ. Change 2001, 11, 261-269.

29. Cao, G.Y.; Chen, G.; Pang, L.H.; Zheng, X.Y.; Nilsson, S. Urban growth in China: Past, prospect, and its impacts. Popul. Env. 2012, 33, 137-160.

30. Lu, Y.; Wang, F. From general discrimination to segmented inequality: Migration and inequality in urban China. Soc. Sci. Res. 2013, 42, 1443-1456.

31. Szabó, G.; Fehér, A. Marginalisation and multifunctional land use in Hungary. J. Agri. Sci. 2004, $15,50-61$.

32. Van Doorn, A.M.; Bakker, M.M. The destination of arable land in a marginal agricultural landscape in South Portugal: An exploration of land use change determinants. Landsc. Ecol. 2007, 22, 1073-1087.

33. Xin, L.J.; Liu, X.B.; Tan, M.B. The rise of ordinary labor wage and its effect on agricultural land use in present China. Geogr. Res. 2011, 30, 1391-1400.

34. Hao, H.G.; Li, X.B.; Zhang, J.P. Impacts of part-time farming on agricultural land use in ecologically-vulnerable areas in North China. J. Resour. Ecol. 2013, 4, 70-79.

35. Thematic Database for Human-earth System. Available online: http://www.data.ac.cn (accessed on 8 January 2013). (In Chinese) 
36. China Meteorological Data Sharing Service System. Available online: http://cdc.cma.gov.cn/ home.do (accessed on 8 January 2013). (In Chinese)

37. ArcGIS, Version 9.3; ESRI: Redlands, CA, USA, 2008.

38. Statistic Bureau of Jiangxi. Available online: http://www.jxstj.gov.cn/Index.shtml (accessed on 8 Janurary 2013). (In Chinese)

39. Li, X. Explanation of land use changes. Prog. Geogr. 2002, 21, 195-203.

40. Angelsen, A. Forest Cover Change in Space and Time: Combining the Von Thünen and Forest Transition Theories; World Bank Publications: Washington, DC, USA, 2007; Volume 4117.

41. Pereira, J.M.C.; Itami, R.M. GIS-based habitat modeling using logistic multiple-regression: A study of the MT Graham Red Squirrel. Photogramm. Eng. Remote Sens. 1991, 57, 1475-1486.

42. Narumalani, S.; Jensen, J.R.; Althausen, J.D.; Burkhalter, S.; Mackey, H.E. Aquatic macrophyte modeling using GIS and logistic multiple regression. Photogramm. Eng. Remote Sens. 1997, 63, 41-49.

43. Garcia, C.V.; Woodard, P.M.; Titus, S.J.; Adamowicz, W.L.; Lee, B.S. A logit model for predicting the daily occurrence of human caused forest-fires. Int. J. Wildland Fire 1995, 5, 101-111.

44. Xie, H. Analysis of regionally ecological land use and its influencing factors based on a logistic regression model in the Beijing-Tianjin-Hebei region, China. Resour. Sci. 2011, 33, 2063-2070.

45. Wang, N.H.; Brown, D.G.; An, L.; Yang, S.; Ligmann-Zielinska, A. Comparative performance of logistic regression and survival analysis for detecting spatial predictors of land-use change. Int. J. Geogr. Inf. Sci. 2013, 27, 1960-1982.

46. Guneralp, B.; Reilly, M.K.; Seto, K.C. Capturing multiscalar feedbacks in urban land change: A coupled system dynamics spatial logistic approach. Environ. Plan. B-Plan. Des. 2012, 39, 858-879.

47. Lin, Y.P.; Chu, H.J.; Wu, C.F.; Verburg, P.H. Predictive ability of logistic regression, auto-logistic regression and neural network models in empirical land-use change modeling-A case study. Int. J. Geogr. Inf. Sci. 2011, 25, 65-87.

48. Gobin, A.; Campling, P.; Feyen, J. Logistic modelling to derive agricultural land use determinants: A case study from southeastern Nigeria. Agric. Ecosyst. Environ. 2002, 89, 213-228.

49. Feiberg, S. The Analysis of Crossclassfied Categorical Data, 2nd ed.; MIT Press: Cambridge, MA, USA, 1980.

50. Hosmer, D.W.; Lemeshow, S. Applied Regression Analysis; Wiley: New York, NY, USA, 1989.

51. SPSS, Version 21.0; SPSS China: Beijing, China, 2013.

52. Wang, J.; Guo, Z. Logistic Regression Model-Methodology and Application; Higher Education Press: Beijing, China, 2001.

53. Akaike, H. Information theory and an extension of the maximum likelihood principle. In Second International Symposium on Information Theory; Peterov, B.N., Caak, F., Eds.; Budapest: Akademiai Kiado, Hungary, 1973; pp. 267-281.

54. Schneider, L.C.; Pontius, R.G. Modeling land-use change in the Ipswich watershed, Massachusetts, USA. Agric. Ecosyst. Environ. 2001, 85, 83-94.

55. Pijanowski, B.C.; Alexandridis, K.T.; Müller, D. Modelling urbanization patterns in two diverse regions of the world. J. Land Use Sci. 2006, 1, 83-108.

56. Maddala, G.S. Introduction to Econometrics; Macmillan: New York, NY, USA, 1988.

57. Menard, S. Applied Logistic Regression Analysis; Sage: Thousand oaks, CA, USA, 1995; Volume 7. 
58. Cai, F.; Du, Y. Report on China's Populaiton and Labor No.8 the Coming Lewisian Turing Point and Its Policy Implications; Social Science Academic Press: Beijing, China, 2007.

59. Shi, T.C.; Li, X.B. Farmland abandonment in Europe and its enlightenment to China. Geogr. Geo. Inf. Sci. 2013, 29, 101-103.

60. Stokstad, G. Exit from Farming and Land Abandonment in Northern Norway; Norwegian Forest and Landscape Institute: Oslo, Norway, 2010.

61. Liu, C.W. Study on the Marginalizaiton of Arable Land in China; Science press: Beijing, China, 2009.

62. Xin, L.J.; Fan, Y.Z.; Tan, M.H.; Jiang, L.G. Review of arable land-use problems in present-day China. Ambio 2009, 38, 112-115.

(C) 2014 by the authors; licensee MDPI, Basel, Switzerland. This article is an open access article distributed under the terms and conditions of the Creative Commons Attribution license (http://creativecommons.org/licenses/by/3.0/). 